\title{
Hydrophobic Sand on the Basis of Superhydrophobic Soot Synthesized in the Flame
}

\author{
B. T. Lesbayev", M. Nazhipkyzy, N. G. Prikhodko, M. G. Solovyova, G. T. Smagulova, \\ G. O. Turesheva, M. Auyelkhankyzy, T. T. Mashan, Z. A. Mansurov \\ The Institute of Combustion Problems, Almaty, Kazakhstan \\ Email: "lesbayev@mail.ru
}

Received October 2013

\begin{abstract}
The paper presents the results of studies on the synthesis of superhydrophobic soot, and on the development of its technology-based production of bulk material (sand), which has hydrophobic properties. The hydrophobic properties of sand had attached by fixing soot having superhydrophobic properties of nanoscale layer on the surface of the grains of sand. The resulting sand was examined by scanning electron microscopy to determine the structural and morphological parameters. The resulting composite material is characterized by good water repellent and resistant to external corrosive environments, which allows it to be used in civil and road construction, water-resistant layer for reclamation in hot and arid regions, and in areas where there is a need for bulk materials with hydrophobic properties.
\end{abstract}

\section{KEYWORDS}

Superhydrophobic; Soot; Nanoscale; Sand

\section{Introduction}

The presence of water in the building or structure leads to the appearance of moisture on the base of the walls, under the floor slabs, rust at the base of steel poles, efflorescence, discoloration or rotting wood panels and other objects near the floor, wall or ceiling, there is mold on concrete, plaster, furniture, carpeting, or wallpaper, efflorescence ("white powder") on concrete; dilapidated floor slabs, the smell of dampness, "fogging” of the walls (condensation or excessive humidity), water condensation on the windows, the growth of moss and the like.

Moisture can penetrate the structure vertically, for example, due to the accumulation of water on the roof or horizontally through the water flowing through the exterior walls of the building due to extreme weather conditions. A major problem is the depth of wall applications where the hydrostatic pressure in the surrounding soil leads to horizontal infiltration of water into the building. The penetration of moisture through the concrete wall due to the porosity of the concrete (about $12 \%$ - 20\%) occurs during the curing process, excess water when creating a network of interconnected capillaries, about 10 $100 \mathrm{~nm}$ in diameter.

Because of the moisture occurs corrosion depth of ob-

${ }^{*}$ Corresponding author. jects, such as underground pipes, gas tanks, tunnels and cables caused by electrolysis of corrosive substances, insects or microorganisms rapidly proliferating in the wet ground it all leads to a considerable reduction of operating these facilities. Waterproofing is also necessary reservoirs, particularly an issue in arid areas, where it is desirable to preserve the contents of the reservoir as long as possible. Almost all of the water, up to $85 \%$, is spent in the desert areas of our planet for irrigation of agricultural land, creating a shortage of water for drinking and hygiene needs, while, according to scientists from the company DIME Hydrophobic Materials, water is consumed irrationally.

Thus, today there is universally recognized need in the hydrophobic composite materials, the production of which would be beneficial, and used effectively.

\section{Experimental}

The combustion of hydrocarbon fuels soot particles are an accessory product of combustion. But if burn fuel under certain conditions, it is possible to produce carbon black with desired properties [1,2]. Globally, every year it produces hundreds of tons of different modifications of carbon black, which are widely used in the production of rubber, paint, components, copiers, as well as carbon 
black is used as a filler in nanocomposite materials. In this paper, the task of creating hydrophobic sand based soot having superhydrophobic properties resulting from the combustion of propane and plastic wastes. This problem is closely related to the study of the conditions of formation of soot having hydrophobic properties during combustion of propane and plastic waste. Industrial manufacturing methods of carbon black based on the decomposition of hydrocarbons under the influence of high temperatures, soot formation occurs in some cases in a flame of burning material with limited access to air, in others-by thermal decomposition of materials in the absence of soot combustion air Preparation materials with limited access of air is essentially in two methods. According to the most popular method for raw materials are burned in furnaces, burners equipped with various devices.

Soot formed in the flame for a certain time (about 6 seconds) is together with the gaseous products of the process in the high temperature zone. Thereafter, the mixture was cooled gases and carbon black and carbon black is separated from the gases in special apparatuses. By the second method, raw materials are burned with burners using a narrow slit, mounted in metal casings. Flat flame was connected with the moving metal surfaces. The time of contact of the flame with the surface is slightly. The precipitated on a metal surface black quickly removed from the area of soot formation. The formation of soot particles can be suspended at a certain level, interrupting the process of its formation. Superhydrophobic properties of soot having applications to create a hydrophobic of sand were prepared using the above principle by the deposition of soot particles on a cold surface, placing it at a certain height of the flame. The photo setup is shown in Figure 1. The principle of the device is based on the deposition of soot particles from the flame on the surface of iron spinning cylinder. A cylinder made of stainless steel, $12.5 \mathrm{~cm}$ diameter $13.5 \mathrm{~cm}$

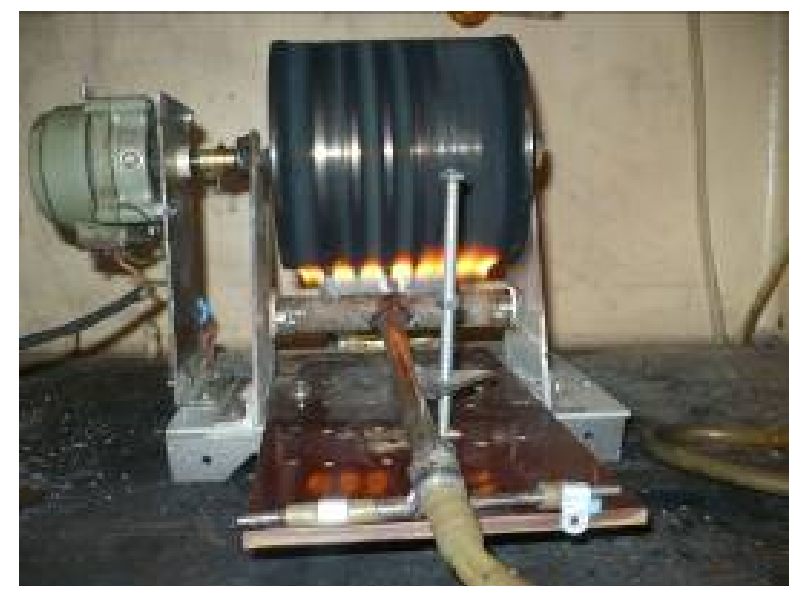

Figure 1. The photo of the experimental setup. height, the speed of $1 / \mathrm{sec}$, the number of nozzles at the burner 7 having a diameter of $2 \mathrm{~mm}$, the flow rate of gaseous feed carbon was $425-500 \mathrm{~cm}^{3} / \mathrm{min}$.

For polyethylene plastic waste flame was placed in a sealed rector and was thermally decomposed without air at a temperature of $900-970 \mathrm{~K}$. The decomposition of polyethylene produced easily condensable gas white color, which, when ignited, burns sustained smoky flame.

On the surface of the iron cylinder is soot deposition thickness of 1 - $1.2 \mathrm{~mm}$. A method for producing superhydrophobic soot proposed method is described in detail in [3].

Technology of production of hydrophobic sand involves several stages. First of all, on the surface of the sand applied adhesive, the next step is to process a hydrophobic carrier. This is followed by curing. Sand of the river was used. As adhesive polyurethane adhesive SD-600, which was dissolved in ethyl acetate was used. The content of the adhesive mass is not more than $5 \%$ by weight of the hydrophobic sand. The adhesive layer applied on the surface by sand settling polyurethane film from the solvent. What sand polyurethane adhesive dissolved in ethyl acetate and subjected to intensive mixing, the volatile solvent evaporates and the sand nanosized film formed of polyurethane. In sand thus obtained is added $1 \%$ superhydrophobic soot resulting mass at $40^{\circ} \mathrm{C}$ - $90^{\circ} \mathrm{C}$ stirred at $60 \mathrm{rev} / \mathrm{sec}$ for 30 minutes. During the stirring surface grains of sand with nanoscale film of a mixture of hydrophobic soot are enveloped.

\section{Results}

The resulting sand has the exclusive hydrophobic property. Figure 2 shows a photograph of the behavior of water droplets on the surface of the resulting hydrophobic sand. The contact angle of water drops is more than 150 degrees.

Were conducted comparing the characteristics of the dynamics of water absorption (Figure 3) taken in the original source sand, sand coated with a polyurethane film's surface and the resulting hydrophobic sand.

For comparison, the original source taken from the sand and the sand coated with the polyurethane absorbs water immediately and completely wetted. Coating the surface prepared hydrophobic sand water distributed over

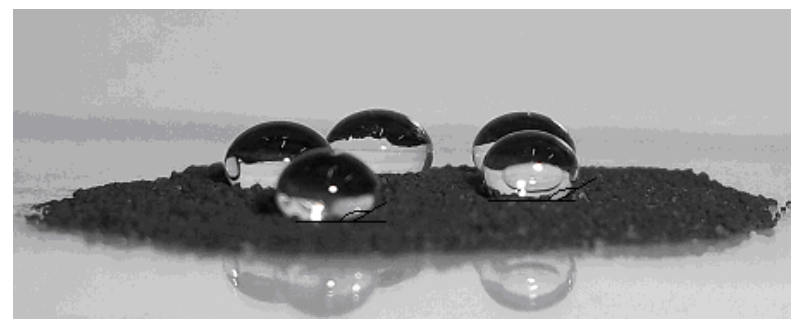

Figure 2. Drops of water on the surface hydrophobic sand. 


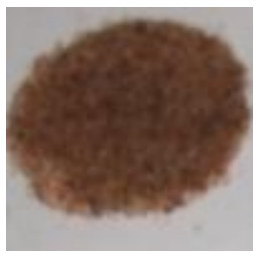

(a)

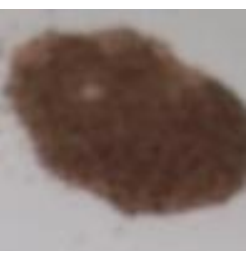

(b)

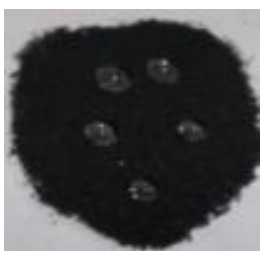

(c)
Figure 3. The dynamics of water absorption: ordinary sand -(a); sand with polyurethanes_-(b); and hydrophobic sand (c).

its surface in the form of droplets and not absorbed hydrophobic sand until its evaporation.

Durability of hydrophobic sand external water pressure was measured. The ability of hydrophobic aggregates to withstand the water pressure is proportional to the cosine of the contact angle and inversely proportional to the radius of the capillary or the radius of the lumen between the grains. In order to measure the ability of the resulting hydrophobic sand withstand the water pressure was carried out the following test. The spout of a long syringe diameter of $1 \mathrm{~cm}^{2}$ cut off so that a homogeneous cylinder. The syringe is inserted into the hydrophobic sand located in the vessel so that a distance from the syringe from any wall was $2 \mathrm{~cm}$ and then a syringe filled with water and inserted into it the plunger. Placing 200 gram load on the piston allowed per day, water pressure remains constant during this period.

Figure 4 shows the behavior of the visibility for the source of sand, sand coated with polyurethane and the resulting hydrophobic sand with her falling asleep in the water. We observe that the resulting hydrophobic sand in an amount of $10 \mathrm{~g}$ of free floats on the water surface.

The resulting sand was investigated by scanning electron microscopy (SEM), electron image is shown in Figure 5. Studies have shown that soot completely envelops the surface of a uniform layer of sand $20 \mathrm{~nm}$. Tests were conducted on the mechanical abrasion of soot particles from the surface of sand. The tests had showed that the soot grains fixed on the surface, and has good adherence, process of stirring for 2 hours does not reduce the film thickness of the soot.

\section{Conclusion}

Thus was perfected procedure for the synthesis of soot having hydrophobic properties during combustion of propane and plastic waste. With the application of the resulting soot created hydrophobic sand, resulting gidofobny sand is proposed to use as a filler in building materials for exterior finishes and in agriculture to prevent seepage of irrigation water in the lower layers of soil or

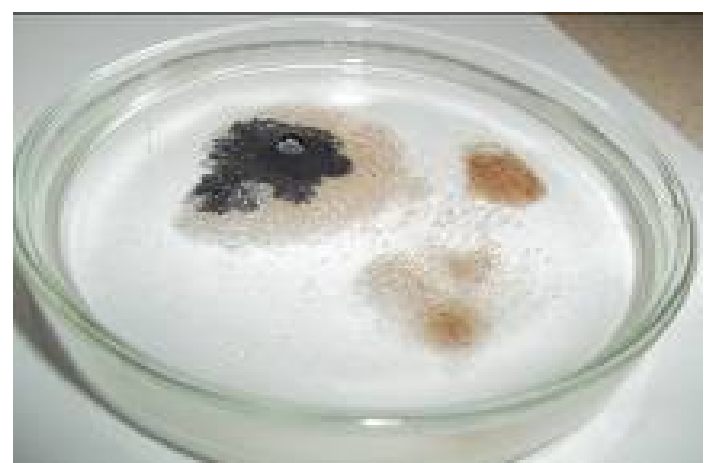

Figure 4. Behavior of sand on the surface.

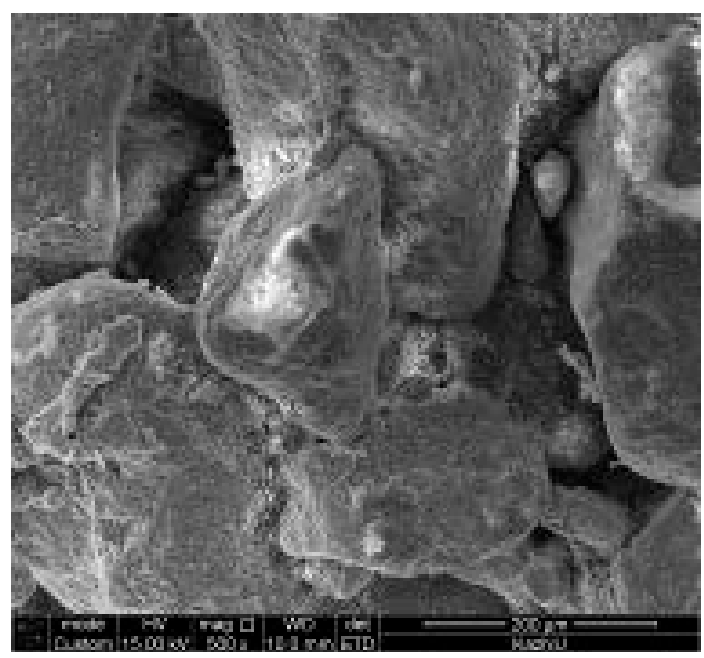

Figure 5. Electron micrograph of the surface of the grains of sand.

evaporation. Also hydrophobic sand can be used for isolation of soil around the plant from the soil and salt saline groundwater, leading to destruction of the root system of the plants.

\section{REFERENCES}

[1] A. Levesque, V. T. Binh, V. Semet, D. Guillot, R. Y. Fillit, M. D. Brookes, et al., "Mono Disperse Carbon Nanopearls in a Foam-Like Arrangement: A New Carbon Nano-Compound for Cold Cathodes," Thin Solid Films, Vol. 464-465, 2004, pp. 308-314.

[2] S. Sen and I. K. Puri, "Flame Synthesis of Carbon Nanofibers and Nanofiber Composites Containing Encapsulated Metal Particles,” Nanotechnology, Vol. 15, No. 3, 2004, pp. 264-268.

[3] Z. A. Mansurov, M. Nazhipkyzy, B. T. Lesbayev, N. G. Prikhodko, T. V. Chernoglazova, D. I. Chenchik and G. T. Smagulova, "Synthesis at Superhydrophobic Soot Flames and its Applied Aspects," World (Intern) Conf. on Carbon, Krakow, 2012, p. 768. 